\title{
Does Aging Matter? The Efficacy of Carpal Tunnel Release in the Elderly
}

\author{
Bettina Wai Yan Fung, Chris Yuk Kwan Tang, Boris Kwok Keung Fung \\ Department of Orthopaedics and Traumatology, University of Hong Kong Medical Centre, Queen Mary Hospital, Pokfulam, Hong Kong
}

Open release remains the gold standard in the treatment of carpal tunnel syndrome in cases where conservative treatment fails. However, the efficacy of carpal tunnel release in the elderly has been debated in the literature throughout the years. This review aims to review the current evidence pertaining to the efficacy of carpal tunnel release in the elderly. Based on the current evidence, the outcome of carpal tunnel release is unpredictable in the elderly. Elderly patients are also less satisfied with the operation compared to younger patients. The authors recommend that these messages be conveyed to elderly patients before surgery. Moreover, open carpal tunnel release should be offered in the early stages of treatment whenever operative management is indicated.

Keywords Carpal tunnel syndrome / Surgery / Nerve compression syndromes

\section{Correspondence:}

Chris Yuk Kwan Tang

Department of Orthopaedics and Traumatology, University of Hong Kong Medical Centre, 5/F, Professorial Block, Queen Mary Hospital, 102 Pokfulam Road, Hong Kong Tel: +852-22554654 Fax: +852-22554654 E-mail: medic.chris.tang@gmail.com

No potential conflict of interest relevant to this article was reported.

Received: 2 Dec 2014 • Revised: 11 Jan 2015 - Accepted: 20 Jan 2015

pISSN: 2234-6163 • elSSN: 2234-6171 • http://dx.doi.org/10.5999/aps.2015.42.3.278 • Arch Plast Surg 2015;42:278-281

\section{INTRODUCTION}

Carpal tunnel syndrome is a compressive neuropathy of the median nerve at the wrist level. It affects $0.1 \%$ of the general population and up to $5 \%$ of those in certain occupations $[1,2]$. It is more common in patients who are older than 55 years old [3]. The elderly (over 65 years of age) have a higher prevalence of severe carpal tunnel syndrome, which correlates with the presence of thenar wasting [4]. Carpal tunnel release is the treatment of choice when conservative treatment fails. The success rate of carpal tunnel release in the general population is in the range of $70 \%$ to $90 \%$, using either the open or endoscopic technique $[5]$.

The rate of axonal regeneration has been shown to be slower and the density of regenerating axons has been shown to decrease in aged animals [6]. An electrophysiological study also showed that age delayed the recovery of distal motor latency af- ter carpal tunnel release [7]. These findings logically lead us to consider whether carpal tunnel release would be less efficacious in elderly patients because it also involves nerve recovery.

Throughout the years, there has been an intense debate regarding the efficacy of carpal tunnel release in elderly patients. This review article presents a summary comparison between preoperative and postoperative symptoms, and also discusses how effectively the surgical procedure improves the symptoms of patients and provides satisfaction for them.

\section{METHODS}

The electronic databases of PubMed, Medline, and the Cochrane library were searched. Articles written in English were included in this review article. The surgical outcome, symptom resolution, functional improvement, self-reported disability, and patient satisfaction were reviewed in order to determine the effi- 
cacy of surgical decompression of the carpel tunnel in the elderly. References in review articles were screened for potentially relevant studies not previously identified.

\section{RESULT AND DISCUSSION}

Open carpal tunnel release is still the gold standard in treating carpal tunnel syndrome, provided that the diagnosis is correct. A 2007 review of the Cochrane database [8] showed there was no strong evidence for replacing the standard open carpal tunnel release procedure with existing alternative surgical procedures. It seemed that the decision to perform endoscopic carpal tunnel release instead of open carpal tunnel release should be guided by the preferences of the surgeon and the patient.

Conflicting evidence exists in the literature regarding whether the outcome of carpal tunnel release is related to increasing age. Katz et al. [9] found that the strongest predictors of less favourable outcomes were worse scores on patient-reported measures of upper extremity functional limitation along with mental health status, alcohol use, and the involvement of an attorney. Increasing age was not found to be related to less favourable outcomes. A prospective study showed no influence of age, gender, or occupation on the outcome of carpal tunnel decompression in a series of 608 carpal tunnel decompressions, as evaluated by the Boston carpal tunnel score [10]. The authors believed that the lack of a difference could be partially accounted for by their exclusion of patients with diabetes mellitus or thyroid disease, as a previous study showed that more than one-fifth of elderly patients had undiagnosed diabetes [11]. Contrastingly, more evidence exists showing that elderly patients have less favourable outcomes as evaluated by the Boston carpal tunnel score. A study in 2013 showed that patients older than 60 years showed less improvement of the total grip strength of the hand after car- pal tunnel release [12]. A total of 386 patients, including patients with diabetes or hypothyroidism, were included in this study. A prospective study involving 87 patients found that improvement in symptoms and function decreased with increasing age, especially in patients more than 60 years old [13]. Another prospective study involving 97 patients in 2005 showed that patients over the age of 70 had a lower postoperative functional score. They were also less satisfied with their treatment than younger patients [14]. However, the authors pointed out that although there was a statistically significant difference between the two groups of patients, the differences in satisfaction were small and the rate of satisfaction in both groups was high (Table 1) [10,12-15].

One study showed improvement in objective measurements after open carpal tunnel release in the elderly, including Phalen's sign, Tinel's sign, two-point discrimination, grip strength, pinch strength, and thenar wasting [16]. Other studies have generally found that the majority of elderly patients experience subjective improvement, as measured by the subjective score of the Boston carpal tunnel score, or satisfaction with the operation rather than objective improvement [17-19]. In one study, elderly patients showed improvement in symptom severity score and functional status score as early as in the six-month postoperative period [17]. Even if the cut-off age is moved to 80 years, Stone et al. [15] showed that the operative outcome and patient satisfaction were similar to the younger control group (less than 80 years old), though the elderly are more likely to have thenar muscle atrophy and a severe nerve conduction deficit at presentation. However, this study used the Quick disabilities of the arm, shoulder and hand score as the outcome measurement, which is less specific for carpal tunnel surgery outcome than the Boston carpal tunnel score. Open carpal tunnel release yielded a satisfactory outcome in all aspects including objective parameters, subjec-

Table 1. Evidence pertaining to open carpal tunnel release in elderly patients

\begin{tabular}{|c|c|c|c|}
\hline Study & Outcome measurement & Exclusion criteria & Conclusion \\
\hline \multicolumn{4}{|c|}{ Results that were less favourable in elderly } \\
\hline Zyluk and Puchalski [12] & BCTS & Recurrent disease & $\begin{array}{l}>60 \text { Years old showed less improvement of total } \\
\text { strength of the hand }\end{array}$ \\
\hline Porter et al. [13] & BCTS & $\begin{array}{l}\text { Diabetes, thyroid disease, } \\
\text { rheumatoid arthritis \& gout }\end{array}$ & $\begin{array}{l}\text { Decreased improvement of symptoms and function in } \\
\text { patients }>60 \text { years old, less patient satisfaction }\end{array}$ \\
\hline Hobby et al. [14] & BCTS & - & $\begin{array}{l}>70 \text { Years old patients showed poorer postoperative } \\
\text { function score (either } 6 \text { weeks or } 6 \text { months) }\end{array}$ \\
\hline \multicolumn{4}{|c|}{ Results that were favourable in elderly } \\
\hline Ibrahim et al. [10] & BCTS & $\begin{array}{l}\text { Diabetes mellitus, thyroid } \\
\text { disease, recurrent disease }\end{array}$ & No difference in age \\
\hline Stone et al. [15] & Quick-DASH & - & $\begin{array}{l}\text { Functional outcome \& patient satisfaction equal in } \\
\geq 80 \text { compared to }<80 \text { years old }\end{array}$ \\
\hline
\end{tabular}


Table 2. Summary of evidence regarding open carpal tunnel release

\begin{tabular}{|c|c|c|}
\hline Aspects & Outcomes in various studies & Outcomes in advanced disease \\
\hline \multicolumn{3}{|l|}{ Clinical } \\
\hline Objective & $\begin{array}{l}\text { Improvement in Phalen's sign, Tinel's sign, 2-point discrimination, } \\
\text { grip strength, pinch strength \& thenar wasting [16] } \\
\text { Average grip strength unchanged [17] }\end{array}$ & \\
\hline \multicolumn{3}{|l|}{ Subjective } \\
\hline Symptoms & $\begin{array}{l}63 \% \text { Relief of all symptoms, } 84 \% \text { relief of paresthesia [16] } \\
\text { Improvement in symptom severity score \& functional status score [17] }\end{array}$ & \\
\hline Satisfaction & $\begin{array}{l}83 \% \text { Satisfied or very satisfied with surgery [16] } \\
94 \% \text { Satisfied with surgery ( } \geq 70 \text { years old) }[18] \\
93 \% \text { Satisfied with surgery ( } \geq 70 \text { years old) }[17]\end{array}$ & $\begin{array}{l}\text { 85\% satisfied or very satisfied with surgery } \\
\text { ( } \geq 70 \text { years old) }[19]\end{array}$ \\
\hline Neurophysiological & $\begin{array}{l}\text { 86\% Electrophysiological improvement at } 1 \text {-year postoperative } \\
\text { period ( } \geq 70 \text { years old) [20] }\end{array}$ & \\
\hline
\end{tabular}

tive parameters, and neurophysiological studies. This evidence is summarized in Table $2[16-18,20]$. However, these studies did not compare the results with younger patients, since a control group of younger patients was lacking in all of these studies.

Subjective outcome scores by patients have been previously shown to be a more sensitive outcome measurement than a traditional physical examination $[9,21]$. As the postoperative outcome is highly determined by patient subjective sensation without any objective test, evaluating the outcome is challenging for surgeons, especially after operations on elderly patients. Numbness in carpal tunnel syndrome is a subjective sensation, which elderly patients may not describe with ideal accuracy, particularly in the Chinese population, as numbness is a quite general term in Chinese. Moreover, the higher prevalence in the elderly of diabetes, hypothyroidism, and cervical spondylosis causing double-crush phenomenon might contribute to less favourable outcomes. Diabetes causes peripheral neuropathy, which can partially account for a patient's symptoms of numbness. The underlying causes of carpal tunnel syndrome, such as hypothyroidism, should also be addressed in addition to mechanical decompression. Elderly patients experience less exertion in routine daily activities, so it might be expected that a lower level of improvement in symptoms and function might be negligible in practice. However, the evidence shows that elderly patients are less satisfied with the carpal tunnel release procedure than their younger counterparts.

Endoscopic carpal tunnel release seems to have less favourable results in elderly patients. Patient age $>65$ years was a good predictor of a less favourable short-term outcome in endoscopic carpal tunnel release but was not relevant for the long-term outcome [22]. After endoscopic carpal tunnel release in elderly patients, touch sensation recovery and subjective sensory disturbance recovery took significantly longer when compared to a younger age group. It was suggested that this could be related to cervical radiculopathy and/or myelopathy due to cervical spondylosis among the elderly group, $89.4 \%$ of which were shown to have cervical spondylosis in an X-ray [23]. Of patients aged 65 or older, $79 \%$ were satisfied or very satisfied with endoscopic carpal tunnel release [24].

Regarding whether the severity of disease would affect the timing of surgery in elderly patients, Aulisa et al. [25] showed in 1998 that complete restoration of clinical and electrophysiological nerve function was observed only in patients with mild carpal tunnel syndrome. However, no relationship was found between the duration of preoperative symptoms, severity of electrophysiological impairment, and relief of symptoms [26]. Even with advanced disease on presentation, $85 \%$ of the elderly patients ( $\geq 70$ years old) were satisfied or very satisfied with surgery [19]. Nevertheless, the authors recommended that decompression be done early in elderly patients, as studies on animal models have shown that nerve regeneration is slower in aged animals [6].

Experiencing some relief from a steroid injection into the carpal tunnel is the best predictor for success of open carpal tunnel release surgery ( $87 \%$ vs. 54\%) [27]. Future studies should be carried out in elderly patients to investigate the predictive value of response to steroid injection as a predictor for success of open carpal tunnel release in elderly patients.

In conclusion, based on the current evidence, the elderly had less predictable symptomatic and functional improvement following open carpal tunnel release when compared to younger patients. The authors suggest that in cases of elderly patients with carpal tunnel syndrome who are planning to undergo an operation, the doctor should thoroughly discuss the fact that elderly patients have more unpredictable outcomes and less satisfaction with the operation compared to younger patients. If a patient prefers operative management after a detailed explanation, open carpal tunnel release should be offered in the early 
stage of the disease, whereas further study is necessary to assess the suitability of endoscopic carpal tunnel release.

\section{REFERENCES}

1. Stevens JC, Sun S, Beard CM, et al. Carpal tunnel syndrome in Rochester, Minnesota, 1961 to 1980. Neurology 1988;38: 134-8.

2. Papanicolaou GD, McCabe SJ, Firrell J. The prevalence and characteristics of nerve compression symptoms in the general population. J Hand Surg Am 2001;26:460-6.

3. Lam N, Thurston A. Association of obesity, gender, age and occupation with carpal tunnel syndrome. Aust N Z J Surg 1998;68:190-3.

4. Seror P. Carpal tunnel syndrome in the elderly: "Beware of severe cases”. Ann Chir Main Memb Super 1991;10:217-25.

5. Katz JN, Keller RB, Simmons BP, et al. Maine Carpal Tunnel Study: outcomes of operative and nonoperative therapy for carpal tunnel syndrome in a community-based cohort. J Hand Surg Am 1998;23:697-710.

6. Verdu E, Ceballos D, Vilches JJ, et al. Influence of aging on peripheral nerve function and regeneration.J Peripher Nerv Syst 2000;5:191-208.

7. Vysata O, Prochazka A, Kunc P, et al. Age delays the recovery of distal motor latency after carpal tunnel syndrome surgery. Acta Neurochir (Wien) 2014;156:1335-9.

8. Scholten RJ, Mink van der Molen A, Uitdehaag BM, et al. Surgical treatment options for carpal tunnel syndrome. Cochrane Database Syst Rev 2007; (4):CD003905.

9. Katz JN, Losina E, Amick BC 3rd, et al. Predictors of outcomes of carpal tunnel release. Arthritis Rheum 2001;44:1184-93.

10. Ibrahim T, Majid I, Clarke M, et al. Outcome of carpal tunnel decompression: the influence of age, gender, and occupation. Int Orthop 2009;33:1305-9.

11. Thomas MC, Walker MK, Emberson JR, et al. Prevalence of undiagnosed Type 2 diabetes and impaired fasting glucose in older British men and women. Diabet Med 2005;22: 789-93.

12. Zyluk A, Puchalski P. A comparison of the results of carpal tunnel release in patients in different age groups. Neurol Neurochir Pol 2013;47:241-6.

13. Porter P, Venkateswaran B, Stephenson H, et al. The influence of age on outcome after operation for the carpal tunnel syndrome: a prospective study. J Bone Joint Surg Br 2002; 84:688-91.

14. Hobby JL, Venkatesh R, Motkur P. The effect of age and gender upon symptoms and surgical outcomes in carpal tunnel syndrome. J Hand Surg Br 2005;30:599-604.
15. Stone OD, Clement ND, Duckworth AD, et al. Carpal tunnel decompression in the super-elderly: functional outcome and patient satisfaction are equal to those of their younger counterparts. Bone Joint J 2014;96:1234-8.

16. Weber RA, Rude MJ. Clinical outcomes of carpal tunnel release in patients 65 and older. J Hand Surg Am 2005;30:7580.

17. Leit ME, Weiser RW, Tomaino MM. Patient-reported outcome after carpal tunnel release for advanced disease: a prospective and longitudinal assessment in patients older than age 70. J Hand Surg Am 2004;29:379-83.

18. Townshend DN, Taylor PK, Gwynne-Jones DP. The outcome of carpal tunnel decompression in elderly patients. J Hand Surg Am 2005;30:500-5.

19. Tomaino MM, Weiser RW. Carpal tunnel release for advanced disease in patients 70 years and older: does outcome from the patient's perspective justify surgery? J Hand Surg Br 2001;26:481-3.

20. Kanatani T, Nagura I, Kurosaka M, et al. Electrophysiological assessment of carpal tunnel syndrome in elderly patients: one-year follow-up study. J Hand Surg Am 2014;39:218891.

21. Amadio PC, Silverstein MD, Ilstrup DM, et al. Outcome assessment for carpal tunnel surgery: the relative responsiveness of generic, arthritis-specific, disease-specific, and physical examination measures. J Hand Surg Am 1996;21:33846.

22. Hansen TB, Larsen K. Age is an important predictor of short-term outcome in endoscopic carpal tunnel release. J Hand Surg Eur Vol 2009;34:660-4.

23. Yoshida A, Okutsu I, Hamanaka I. Comparison of clinical results between elderly and younger patients following endoscopic carpal tunnel release surgery for idiopathic carpal tunnel syndrome. Hand Surg 2013;18:59-61.

24. Beck JD, Wingert NC, Rutter MR, et al. Clinical outcomes of endoscopic carpal tunnel release in patients 65 and over. J Hand Surg Am 2013;38:1524-9.

25. Aulisa L, Tamburrelli F, Padua R, et al. Carpal tunnel syndrome: indication for surgical treatment based on electrophysiologic study.J Hand Surg Am 1998;23:687-91.

26. Longstaff L, Milner RH, O’Sullivan S, et al. Carpal tunnel syndrome: the correlation between outcome, symptoms and nerve conduction study findings. J Hand Surg Br 2001; 26:475-80.

27. Edgell SE, McCabe SJ, Breidenbach WC, et al. Predicting the outcome of carpal tunnel release.J Hand Surg Am 2003; 28:255-61. 